\title{
Barefoot and High-Heeled Gait: Changes in Muscles Activation Patterns
}

\author{
Nathalya Ingrid Cardoso do Nascimento', Thaís Sepêda Saraiva1, \\ Alex Tadeu Viana da Cruz Jr. ${ }^{1}$, Givago da Silva Souza ${ }^{2,3}$, Bianca Callegari1 ${ }^{*}$ \\ ${ }^{1}$ Institute of Health Sciences, Federal University of Pará, Belém, Brazil \\ ${ }^{2}$ Institute of Biological Sciences, Federal University of Pará, Belém, Brazil \\ ${ }^{3}$ Center for Tropical Medicine, Federal University of Pará, Belém, Brazil \\ Email: ${ }^{\text {callegaribi@uol.com.br }}$
}

Received 9 July 2014; revised 24 August 2014; accepted 7 September 2014

Copyright (C) 2014 by authors and Scientific Research Publishing Inc.

This work is licensed under the Creative Commons Attribution International License (CC BY). http://creativecommons.org/licenses/by/4.0/

(c) (i) Open Access

\begin{abstract}
Most women like wearing high-heeled shoes for the benefit of sensuous attractiveness and selfesteem while musculoskeletal problems and gait patterns changes are often associated. The present study aimed to identify changes during the gait stance and swing phases in some lower limb muscles. In addition, abdominal muscle was included due to its importance in dynamic trunk stability, and lack of studies on the subject. Here, we found that the use of high-heeled shoes elicited not only the increasing of the electrical activity from the muscles involved in the gait cycle, but also altered the temporal sequence of their recruitment. As practical applications, these changes may be strategies to maintain stability and minimize risks of falling, but they are often associated to diseases. Women that use high-heeled shoes for prolonged time must apply specific muscle exercises to minimize its long-term effects.
\end{abstract}

\section{Keywords}

Human Gait, High-Heeled Shoes, Lower Limb Muscles, Temporal Activation, Electromyography

\section{Introduction}

Most women agree that wearing high-heeled shoes provides a sense of self-esteem and psychological well-being, which makes this kind of footwear widely used by them, at different times of their lives. The use of high heels shoes is, and will always be, a common practice among western women.

Nevertheless, some researchers have reported that the use of these shoes has consequent negative effects.

\footnotetext{
${ }^{*}$ Corresponding author.
}

How to cite this paper: do Nascimento, N.I.C., Saraiva, T.S., da Cruz Jr., A.T.V., da Silva Souza, G. and Callegari, B. (2014) Barefoot and High-Heeled Gait: Changes in Muscles Activation Patterns. Health, 6, 2190-2196. 
Studies suggested that the use of heels can contribute to the development and progression of knee pain [1] [2], an increased predisposition toward degenerative knee osteoarthritis [2] [3], low back pain due to increased spinal curvature [4] [5], and changes in gait pattern, such as walking speed and mobility [6].

The risks assigned to the prolonged use of high heels, and its popularity among the female population have stimulated studies focused in the characteristics of these shoes and its consequences for the musculoskeletal system.

Human gait represents a bipedal, biphasic forward propulsion in which there are alternate and cyclic movements of different segments from the body [7]. One cycle is divided into stance and swing phases, and describes the motions from initial placement of the supporting heel on the ground, to when the same heel contacts the ground for a second time [8].

In normal gait, the muscles work in a functional synergy, defined as a pattern of co-activation, and play an important role in walking speed control, by reducing or increasing the braking impulse. Furthermore, their action enables damping of shocks and vibrations, which reduces the lower limbs impact forces, thereby protecting against overuse injuries [8] [9].

Studies have shown that wearing high-heeled shoes modifies the normal gait and imposes non-physiological conditions to the muscles and joints. This leads to increased metabolic cost and muscle loading, and can accelerate muscle fatigue [1] [10].

Previous studies demonstrated that prolonged use of high-heeled shoes increases plantarflexion, and leads to limited gas trocnemius (GA) and soleus (SL) extensibility, as well as changes their activation pattern [1] [11]. Changes in the behaviour of its main antagonist, the tibialis anterior (TA), however, are still controversial [1] [12] [13].

Experimental results also showed an increased knee joint flexion during stance phase of high-heeled gait, which leads to higher knee extensor activation. It is speculated that this may be one reason for the greater incidence of osteoarthritis in the knee joint of women comparing to men [2] [14] [15].

Although no agreement on some issues, there is no doubt the biomechanics and muscle activity are significantly changed during high-heeled walking when comparing to normal walking. Studies on muscle action are still required to elucidate the question, not only related to its magnitude or power, but also to participation of each muscle during the cycle (onset/offset assessment).

In this study, we aimed to identify changes, imposed by the use of high heels, in the activation behaviour of some lower limb muscles during the stance and swing phases. Authors expect changes in amplitude and activation timing during high heels gait as strategies to minimize the risk of falling, the improve stability of the body and prevent injuries.

Moreover, due to the importance of abdominal muscle activity in dynamic trunk stability, assessing the effects on activation of rectus abdominis, not yet described in the literature, was also included.

\section{Materials and Methods}

\subsection{Participants}

This study aimed to investigate a young homogenous asymptomatic population. Table 1 summarizes the demographic data for the 20 females subjects selected in our sample. Individuals were similar regarding age, weight, height, and body mass index. They were voluntary students from the city of Macapá. The volunteers were caucasian and declared themselves sedentary when interviewed for the research, which lasted from February to November, 2012.

Table 1. Demographic characteristics of the study population.

\begin{tabular}{cc}
\hline Variables & Mean (SD) \\
\hline Age (years) & $19.7(2.0)$ \\
Weight $(\mathrm{Kg})$ & $62.7(14.6)$ \\
Height $(\mathrm{m})$ & $1.68(1.60 / 1.71)$ \\
BMI $\left(\mathrm{Kg} / \mathrm{m}^{2}\right)$ & $22.3(1.3)$ \\
\hline
\end{tabular}

SD: standard deviation. BMI: body mass index. 
Participants had the same shoe size ( $6_{1 / 2}$, US/Canada standard) and were included if they had a body mass index (BMI) of bellow 25 to minimize potential signal artefact from fat tissue. Also, they were inexperienced wearers of high-heeled shoes (i.e. less than 4 hours per week) (14). No subject suffered from neuromuscular or musculoskeletal disorders and they were excluded if had previous episodes of pain or dysfunction in the six months prior to recruitment, or in case of pregnancy. Ethics Committee of Seama faculty approved this study (Protocol 061/08) and all participants gave their informed consent before participation. Participants under 18 had their informed consent by parents. All research data, including right to withdraw and protection from harm were ensured.

\subsection{Equipments}

Electromyographic activity was conducted using the device EMG System do Brasil ${ }^{\circledR}$, which consists of an analogic-digital converter of 8 channels, with 16 bits of resolution and input range from -12 to +12 volts. Each channel is coupled to two active bipolar circular electrodes (Meditrace-Ag/AgCl), of $10 \mathrm{~mm}$ diameter, placed in pairs separated by $2 \mathrm{~cm}$.

A computer was connected to the EMG equipment (high-impedance pre-amplifying system) with a gain of 20 times. Data were sampled at $2000 \mathrm{~Hz}$, band-pass filtered $(20-450 \mathrm{~Hz})$, and analyzed using a pre-specified routine programmed in MatLab (Matlab 2008a, Math Works Inc., MA).

EMG signal were rectified and subsequently quantified as root mean square (RMS) over a 300 ms window. Data obtained during gait were also normalized to maximum voluntary isometric contraction (MVC) data obtained in trials prior to gait acquisitions. Finally, the linear envelope of each muscle was calculated using a second order Butterworth low-pass filter (6 Hz cut-off).

Time normalization of EMG gait data to \% gait cycle was performed assuming that gait cycles are periodic and assigns consecutive ipsilateral heel strikes to $0 \%$ and $100 \%$ gait cycle. For that, a digital camera (model DSC W-560, Sony) was synchronized to the acquisition system for recording the motion in the sagittal plane. We used images to identify the exact time of initial contact and loss of foot contact with the ground, thereby determining cycle phases.

To detect muscular activation, we used a criteria for establishing the onset and offset activation based on a voltage threshold (2 standards deviation beyond mean of baseline) [16]. In situations when this initial process was not able to identify onset activation, the muscles were considered activated when EMG signal exceeded 20\% of the minimum amplitude of the signal average per individual [16].

The shoes in this study were commercially available (Vizzano, Brazil), bought with $6_{1 / 2}$ sized (US/Canada standard), with $7 \mathrm{~cm}$ stiletto heels.

The recordings were analysed using the period of muscle activation (\%) during the gait cycle, and the RMS (\% $\mathrm{MVC}$ ) in the stance and swing phases. Variables were compared between the barefoot and high-heeled gait.

\subsection{Procedures}

All measurements were performed during gait on a flat walkway, made of ethylene vinyl acetate (EVA), with seven meters.

Volunteers were asked to walk with natural and self-selected speed, firstly on barefoot and then with high-heeled shoes.

The assessed muscles were gastrocnemius medialis (GA), rectus femoris (RF), tibialisanterior (TA) and rectus abdominis (RA). The reference electrode was positioned on the spinous process of C7. All procedures were taken according to the recommendations of SENIAM regarding skin preparation, position of patient and testing connection (Surface EMG for a non-invasive assessment of muscles) [17].

Three tests of MVC for each muscle were performed. The contractions were maintained for 5 seconds with 1 minute rest between them. The average of the three tests was used for normalization of the electrical activity obtained during gait [18].

\subsection{Statistical Analysis}

Data were tested for normality using Shapiro-Wilk test. Variables normally distributed were compared using the t Test (RF and TA data). Variables not normally distributed were compared using the Mann Whitney test (GA e RA). Significance level was established for $p<0.05$. All tests were conducted using Bio Stat 5.0. 


\section{Results}

Figure 1 shows the RMS amplitude of each muscle during the stance and swing phases of the gait cycle using the high-heeled shoes and barefoot. During the stance and swing phase, all the muscles had increased RMS amplitude compared their activity without shoes.

Table 2 shows the duration time of activation of each muscle during the gait cycle. GA and RF had participated for longer period during gait cycle, when wearing high-heel shoes. RA had less duration time of activation when the subject was wearing the high-heeled shoes compared to the barefoot walking. TA had non-significant differences in the duration time of activation for both situations.

\section{Discussion}

In the present study, we showed that the use of high-heeled shoes elicited not only the increasing of the electrical activity from the muscles involved in the gait cycle, but it altered the temporal sequence of recruitment of them.
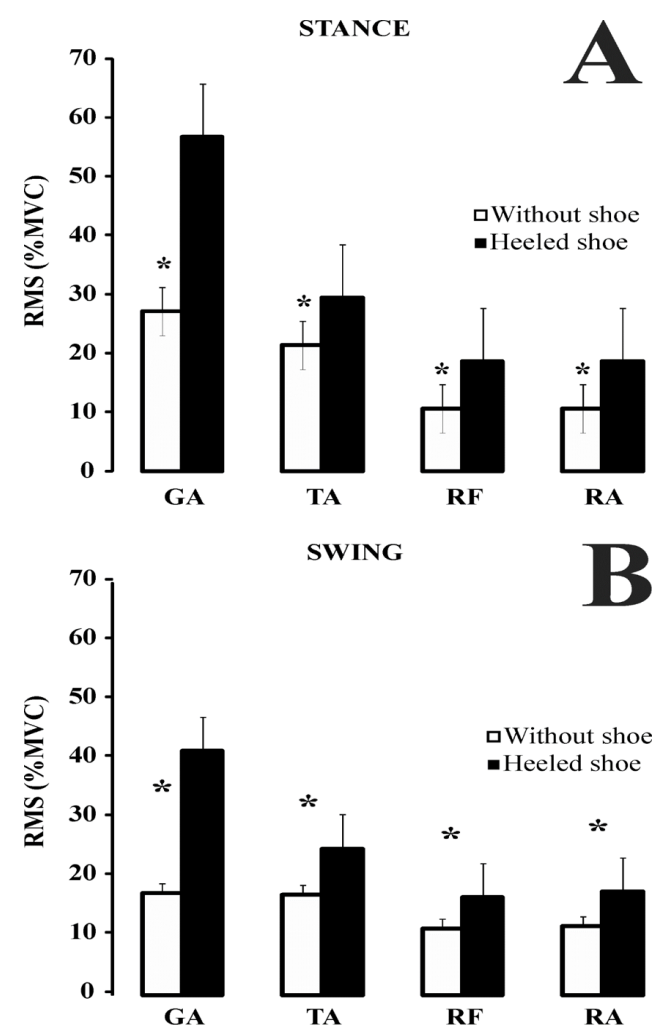

Figure 1. Electrical activity shown as RMS (\%MVC), in stance phase (A) and swing phase (B). Statistical significance $\left(^{*}\right) \mathrm{p}<0.05$.

Table 2. Muscle activation duration (\% gait cycle).

\begin{tabular}{cccc}
\multicolumn{3}{c}{ ONSET } & \\
\hline HH & BF & p-value \\
\hline GA & $67.8 \pm 14.6$ & $45.5 \pm 11.7$ & $\mathrm{p}<0.0001^{*}$ \\
RA & $77.4 \pm 19.3$ & $83.2 \pm 20.8$ & $\mathrm{p}=0.027^{*}$ \\
RF & $59.4 \pm 19.4$ & $42.8 \pm 19.3$ & $\mathrm{p}=0.0022^{*}$ \\
TA & $55 \pm 21.1$ & $60 \pm 21.2$ & $\mathrm{p}=0.18$ \\
\hline
\end{tabular}

HH, High-heeled gait. BF, Barefoot gait. Statistical significance $\left(^{*}\right) \mathrm{p}<0.05$. 
All the muscles in the present study had higher activation as observed by the increased electrical activity during the use of high-heeled shoes. Postural adaptation such as exaggerated plantar flexion of foot [10], increasing of the flexor moment of knee [13], and displacement of the center of gravity [18] increase the instability during the high-heeled gait and could lead to the muscle recruitment as we observed.

Our study agreed with previous investigations that quantified the RMS amplitude of RF, GA and TA, which also concluded about the higher recruitment of them [1] [10] [13]. It was suggested that the higher activation of the quadriceps muscle during the high-heeled gait was due the higher flexor moment of knee [6] [13]. It was also observed that GA had increased activity during the high-heeled gait that could predispose to its shortening [11].

Candotti et al. (2012) explained that GA is the highly recruited during the use of high-heeled shoes due to the anterior projection of the body weight forward to forefoot. They demonstrated the higher the heel height, the higher the GA recruitment [10].

The instability of ankle during the high-heeled gait leads to the co-activation of plantar and dorsal flexor of the foot [5]. The changes in the TA muscle during the high-heeled gait are controversial in the literature. Some studies found no changes during the high-heeled gait. They suggested that the amplitude of dorsiflexion is smaller using high-heeled shoes than with regular shoes, not affecting the TA activation [10] [19]. However, Aljkaer et al. (2012) found higher activity of TA muscle during the stance phase of high-heeled gait, and depressed activity during its swing phase [5]. Hong et al. (2013) also showed RMS increasing of TA in the stance phase during the high-heeled gait due the stabilization of ankle in this phase. They suggested that the load on the muscle could provoke an earlier fatigue and limited endurance [12]. Johanson et al. (2010) found higher activity of TA muscle during both phases of the high-heeled gait and they justified that the same muscle is a controller of the foot pronation in the beginning of the stance phase [11]. Our study also found higher recruitment during both phases of the high-heeled gait.

Even though the RA is a priority muscle in stabilization of the trunk, this muscle is few included in the investigations of the human gait. Here, it showed higher RMS amplitude during both phases of the high-heeled gait. It was shown that the higher activity of the posterior muscles of the trunk in response to the anterior displacement of the centre of gravity provoked by the heeled-shoes [4] [19] [20]. Barton et al. (2009) compared the EMG from erector spinae muscles and the obliquus abdominis muscle. They observed a higher increasing of the posterior muscle activity. They suggested the inclusion of RA in future investigation [4]. In spite of that, we observed in the present study, some studies investigated the RA activity during the use of high-heeled shoes and stated that the gait did not alter the recruitment of this muscle [20] [21].

We also quantified the temporal activation of the muscles during the gait. In spite of the increasedRMS amplitude, we observed that the longer duration time of muscle activation during the gait cycle occurred only for GA and RF, while RA and TA had smaller duration of their activation using high-heeled shoes. It means that although the muscles have been highly recruited, their timing analysis varied between the situations of gait.

Our results agreed with previous investigations about the duration of muscle activation [1] [13]. Prolonged plantar flexion of the foot and high flexion of the knee could justify our results [13].

RA muscle also was smaller duration of activation during the high-heeled gait. We did find no other study describing the temporal activation of RA during gait to compare with our results. But, we suggest that the activation of the erectors of the spinae muscles demonstrated by some investigations [4] [20] could lead to a reflex inactivation of RA.

The shorter participation of RA during the gait cycle wearing high-heeled shoes can be associated with the high incidence of back pain in women that used this kind of shoe [21].

\section{Conclusion}

We suggest that the changes described in the present study are strategies to minimize risks of falling and to keep the stability of the body. However, the changes are necessary during the use of high-heeled shoes which can be associated to injuries. Women that use high-heeled shoes for prolonged time might do specific muscle exercises to minimize its long-term effects. Our limitations stopped on the abdominal muscle due to lack of studies in the literature on this type of analysis. In future studies, it would be necessary for a greater number of subjects for the study of abdominal muscles and stabilizers of the trunk. 


\section{Acknowledgements}

Supported by: MS/FAPESPA/PPSUS \#003/2012.

\section{References}

[1] Mika, A., Oleksy, Ł., Mika, P., Marchewka, A. and Clark, B.C. (2012) The Influence of Heel Height on Lower Extremity Kinematics and Leg Muscle Activity during Gait in Young and Middle-Aged Women. Gait \& Posture, 35, 677-680. http://dx.doi.org/10.1016/j.gaitpost.2011.12.001

[2] Kerrigan, D.C., Todd, M.K. and Riley, P.O. (1998) Knee Osteoarthritis and High-Heeled Shoes. The Lancet, 351, 1399-1401. http://dx.doi.org/10.1016/S0140-6736(97)11281-8

[3] Kerrigan, D.C., Johansson, J.L., Bryant, M.G., Boxer, J.A., Della Croce, U. and Riley, P.O. (2005) Moderate-Heeled Shoes and Knee Joint Torques Relevant to the Development and Progression of Knee Osteoarthritis. Archives of Physical Medicine and Rehabilitation, 86, 871-875. http://dx.doi.org/10.1016/j.apmr.2004.09.018

[4] Barton, C.J., Coyle, J.A. and Tinley, P. (2009) The Effect of Heel Lifts on Trunk Muscle Activation during Gait: A Study of Young Healthy Females. Journal of Electromyography and Kinesiology, 19, 598-606. http://dx.doi.org/10.1016/j.jelekin.2008.03.001

[5] Nam, S.J., Kim, M.J., Yim, S.J., Oh, D.W., Park, H.J. and Kim, C.Y. (2014) Influence of Walking Speed on Electromyographic Activity of the Rectus Abdominis and Erector Spinae during High-Heeled Walking. Journal of Back and Musculoskeletal Rehabilitation, 27, 355-360.

[6] Alkjær, T., Raffalt, P., Petersen, N.C. and Simonsen, E.B. (2012) Movement Behavior of High-Heeled Walking: How Does the Nervous System Control the Ankle Joint during an Unstable Walking Condition? PLoS One, 7, e37390. http://dx.doi.org/10.1371/journal.pone.0037390

[7] Vaughan, C.L., Davis, B.L. and O’Connor, J.C. (1992) Dynamics of Human Gait. 2nd Edition, Kiboho Publishers.

[8] Rose, J. and Gamble, J.G. (2006) Marcha, Teoria e Prática da Locomoção Humana. 3rd Edition, Guanabara Koogan, Rio de Janeiro.

[9] Viel, E. (2001) A Marcha Humana, a Corrida e o Salto. Manole, São Paulo.

[10] Cronin, N.J., Barrett, R.S. and Carty, C.P. (2012) Long-Term Use of High-Heeled Shoes Alters the Neuromechanics of Human Walking. Journal of Applied Physiology, 112, 1054-1058. http://dx.doi.org/10.1152/japplphysiol.01402.2011

[11] Candotti, C., Carvalho, K., Torre, M., Noll, M. and Varela, M. (2012) Ativação e co-contração dos músculos gastrocnêmio e tibial anterior na marcha de mulheres utilizando diferentes alturas de saltos. Rev. Bras. Ciênc. Esporte, 34, 27-39.

[12] Johanson, M.A., Allen, J.C., Matsumoto, M., Ueda, Y. and Wilcher, K.M. (2010) Effect of Heel Lifts on Plantarflexor and Dorsiflexor Activity during Gait. Foot \& Ankle International, 31, 1014-1020. http://dx.doi.org/10.3113/FAI.2010.1014

[13] Hong, W.H., Lee, Y.H., Lin, Y.H., Tang, S.F. and Chen, H.C. (2013) Effect of Shoe Heel Height and Total-Contact Insert on Muscle Loading and Foot Stability While Walking. Foot \& Ankle International, 34, 273-281. http://dx.doi.org/10.1177/1071100712465817

[14] Simonsen, E.B., Svendsen, M.B., Nørreslet, A., Baldvinsson, H.K., Heilskov-Hansen, T., Larsen, P.K., Alkjær, T. and Henriksen, M. (2012) Walking on High Heels Changes Muscle Activity and the Dynamics of Human Walking Significantly. Journal of Applied Biomechanics, 28, 20-28.

[15] Esenyel, M., Walsh, K., Walden, J.G. and Gitter, A. (2003) Kinetics of High-Heeled Gait. Journal of the American Podiatric Medical Association, 93, 27-32.

[16] Chang, W.N., Lipton, J.S., Tsirikos, A.I. and Miller, F. (2007) Kinesiological Surface Electromyography in Normal Children: Range of Normal Activity and Pattern Analysis. Journal of Electromyography and Kinesiology, 17, 437-445. http://dx.doi.org/10.1016/j.jelekin.2006.02.003

[17] Hermens, H.J., Freriks, B., Disselhorst-Klug, C. and Rau, G. (2000) Development of Recommendations for SEMG Sensors and Sensor Placement Procedures. Journal of Electromyography and Kinesiology, 10, 361-374. http://dx.doi.org/10.1016/S1050-6411(00)00027-4

[18] Burden, A. and Bartlett, R. (1999) Normalisation of EMG Amplitude: An Evaluation and Comparison of Old and New Methods. Medical Engineering \& Physics, 21, 247-257.

[19] Lee, C.M., Jeong, E.H. and Freivalds, A. (2001) Biomechanical Effects of Wearing High-Heeled Shoes. International Journal of Industrial Ergonomics, 28, 321-326.

[20] Foster, A., Blanchette, M.G., Chou, Y.C. and Powers, C.M. (2012) The Influence of Heel Height on Frontal Plane Ankle Biomechanics: Implications for Lateral Ankle Sprains. Foot \& Ankle International, 33, 64-69. 
[21] Sundstrup, E., Jakobsen, M.D., Andersen, C.H., Jay, K. and Andersen, L.L. (2012) Swiss Ball Abdominal Crunch with Added Elastic Resistance Is an Effective Alternative to Training Machines. International Journal of Sports Physical Therapy, 7, 372-380.

\section{Abbreviations}

TA: Tibialis anterior

GA: Gastrocnemiusmedialis

RF: Rectus femoris

RA: Rectus abdominis

MVIC: maximum voluntary isometric contraction

TA: Tibialis anterior

GA: Gastrocnemiusmedialis

RF: Rectus femoris

RA: Rectus abdominis

MVIC: maximum voluntary isometric contraction

SL: Soleus

EMG: Eletromyography

RMS: Root mean square 
Scientific Research Publishing (SCIRP) is one of the largest Open Access journal publishers. It is currently publishing more than 200 open access, online, peer-reviewed journals covering a wide range of academic disciplines. SCIRP serves the worldwide academic communities and contributes to the progress and application of science with its publication.

Other selected journals from SCIRP are listed as below. Submit your manuscript to us via either submit@scirp.org or Online Submission Portal.
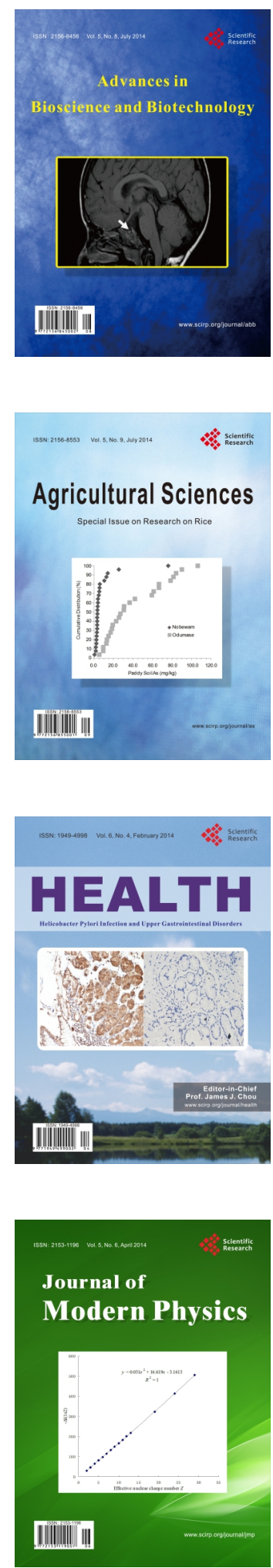
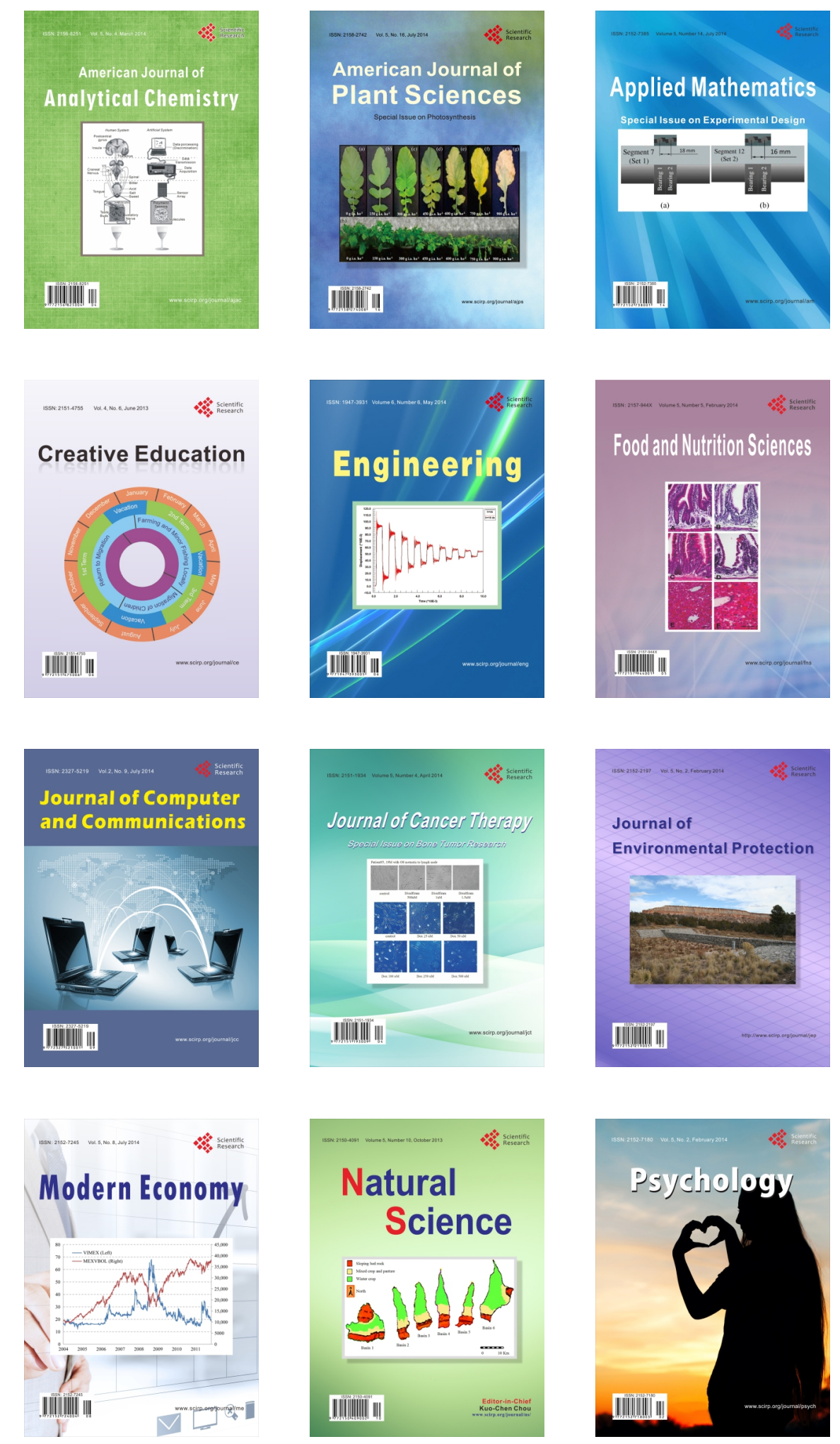